\title{
Etiological Treatment for Infection by Trypanosoma cruzi
}

\author{
Vicente Amato Neto \\ Laboratório de Parasitologia, Instituto de Medicina Tropical de São Paulo, Av. Dr. Eneas de Carvalho Aguiar \\ 470, 05403-000, São Paulo, SP, Brasil
}

Key words: Trypanosoma cruzi infection - etiological treatment

In treating infectious or parasitic diseases it is very important to be able to count on efficient medicines in order to fight the cause. In terms of infection caused by Trypanosoma cruzi, the Chagas disease, this is no different. Nevertheless, since the discovery of this disease ninety years ago this important objective has not been completely reached regardless of research done which although intense, could have been more consistent.

Regarding the protozoosis in question, it is necessary to recognize that various aspects are deserving of detailed attention, from which important information can be gained. I refer to etiology, epidemiology including alternative transmission mechanisms, laboratory diagnosis, delineation of clinical dynamics and prevention. It is also worth making it clear that immunological and pathological contingencies, developed by various researchers, have yet to lead to irrefutable conclusions, which has prevented the implementation of any method capable of counteracting the damage caused by the T. cruzi. So specific treatment, currently co-operative in certain circumstances, needs considerable development.

There are three types of medicine available these days: benznidazole, nifurtimox and allopurinol. The second is not being sold in Brazil and the third can electively slow down parasitic reactivation in people with immunodeficiency (Levi et al. 1996, Souza et al. 1998). However the latter, along with itraconazole, are still considered controversial as a way of treating patients in the acute and chronic phases or people with immunodeficiency.

Benznidazole and nifurtimox should be prescribed for patients that are in the acute stage of the disease whatever the means of the transmission might have been. Even a parasitological cure can occur as seen in uneven percentages registered

Fax: +55-11-881.8158. E-mail: amatonet@usp.br Received 9 June 1999

Accepted 9 August 1999 in different regions, if we accept that strains or parasite resistance are linked to this. Another irrefutable sign refers to the treatment of victims of laboratory accidents, which demands a very early start to the administration.

Organ transplants have brought about discussions as to the efficiency of anti-T. cruzi drugs to the fore-front. Infected donors can pass on the protozoa to receptors, as has been documented in the case of kidneys. The two compounds mentioned above can, on occasion, diminish the intensity of the parasitosis. If the receptor has been infected with Chagas through a kidney or heart transplant, also as in immunodeficiency of another nature, a parasitical reactivation is expected. Benznidazole, nifurtimox and allopurinol on such occasions proved to be able to reduce the exarcebation, giving another valid indication for the aforementioned medicaments (Amato Neto et al. 1995, Rassi et al. 1998).

Infection of the human immunodeficiency virus (HIV) and its consequence, the acquired immunodeficiency syndrome (Aids), have, over recent years, given rise to yet another important concern. The binomial HIV-T. cruzi is seemingly common, and everything indicates that it will slowly become more increasing, which will consequently result in a greater number of immunologically suppressed people. This favors the reactivation of the parasitic infection responsible for the serious nature in most events where intense myocarditis is present and also reactions occurring in the central nervous system (Sartori et al. 1998). Benznidazole, for the most part, as well as other medicaments, sporadically and speculatively, were used to help these patients without any noticeable or tranquilizing success.

Recently there have been three meetings organized by the Ministry of Health, the World Health Organization and The Brazilian Society of Tropical Medicine, aimed at collecting experiences and evaluating the real possibilities of the known drugs used in the specific etiological treatment of Chagas disease. Several professionals interested in this type of therapy were present. Besides the above recommendations, two new pieces of information were 
added: the cure of chronically ill children up to the age of 12 using benznidazole; plus the importance in treating people in the chronic stage since antiparasitic activity can prevent the clinical evolution of the parasitic process, always bearing in mind that the importance of valuing the participation of the etiological agent and the interpretation of clinical data should never be excluded in parasitologic control. In one of the meetings there was general approval for a proposal, supported by WHO, which suggested that the administration of antiparasitic drugs in the chronic stage was a valid option, taking into consideration the late start without considerable damage, where patients are adults generally. Nonetheless there was a recommendation against generalizations where each case should be treated individually.

Drug dosage and administration periods were not regular for the different cases. However in an attempt to provide some guidance and after taking into consideration the total number of observations carried out, a group of very experienced professionals reached consensus in establishing a recommendable dosage which was endorsed by the Ministry of Health. They are as follows: to prevent infection caused by T. cruzi through a laboratory accident and, maybe, after blood transfusion from a donor infected with Chagas - benznidazole, 7 to $10 \mathrm{mg} / \mathrm{kg}$ for 10 days; as treatment - benznidazole (adults), $5 \mathrm{mg} / \mathrm{kg}$ a day for 60 days and benznidazole (children), 5 to $10 \mathrm{mg} / \mathrm{kg}$ a day for 60 days with the daily dosage being divided into two or three parts at intervals of 8 or $12 \mathrm{hr}$; as treatment - nifurtimox (adults), 8 to $10 \mathrm{mg} / \mathrm{kg}$ a day for 60 to 90 days; and nifurtimox (children), 15 $\mathrm{mg} / \mathrm{kg}$ a day for 60 to 90 days, dividing the daily dosage into three parts at intervals of $8 \mathrm{hr}$. Benznidazole is the most commonly used drug and the nifurtimox can not be found in Brazil.

It might be interesting to know, as I recall, that in Argentina a governmental decree has determined widespread treatment of all infected people that are in the chronic stage.

There has been constant interest in knowing if medicaments can prevent disorders from becoming more intense. Anis Rassi has kindly supplied me with a summary of his studies, carried out since 1987 , concerning the use of benznidazole.

Despite several hypotheses as to how the $T$. cruzi pathogenically causes the Chagas disease, there is a growing belief that this parasite, as a basic infectious agent, is prominent in the process, which leads us to conclude that it deserves to be properly addressed and such an interpretation concedes relevant importance to the etiological treatment. Therefore, whenever we turn our attention to cardiopathy it is important to remember what has been achieved through this type of treatment using benznidazole in chronically ill patients. For instance, through the analysis of several reports on children and adults that have been carefully watched over a period of 3 to 16 years it was possible to see that cardiopathy had evolved by between $1.7 \%$ and $13.3 \%$ among treated patients, whereas patients who did not receive benznidazole registered rates of between $6.9 \%$ and $63.3 \%$.

If one considers the whole spectrum of results received from various scientific sources, with regards to the medicaments applied, especially benznidazole and nifurtimox, it is possible to point to the following percentages of cure obtained through negative results from xenodiagnosis and serological tests (Elisa; complement fixation; hemagglutination; immunofluorescence) that have altered the natural evolution of the disease: acute phase $-70 \%$; recent chronic phase $-60 \%$; long term chronic phase $-20 \%$.

Treatment during pregnancy in an effort to prevent congenital infection, medicating infected donors and treatment of receptors with preventative antiparasitic drugs previous to any possible transplant are all procedures that depend either on new medicine or supporting research which could bring about proposals for long or periodical use of these drugs.

The post-treatment control of Chagas is no easy task and this makes a difference when compared to other diseases. There are many peculiarities and the continuing presence of antibodies in the chronic phase is one of the most intriguing.

It is important to emphasize that what is aimed at here is improvement in the chronic stage. The methods applied in the acute phase are reliable where clinical, parasitological and serological evaluations are useful and well known. Despite this, in the posterior phase we often see a lack of a rigorous approach regarding hemoculture, inoculation in animals, xenodiagnosis and tests which identify the presence of antibodies in the serum. These are tests which need to be repeated many times over a long period of time. The complement mediated lyse technique, recommended as co-operative, is not fully recognized by several researchers. The moment calls for progress and suggestions point, for example, to the use of the polymerase chain reaction (PCR), connotations with cytokines and tumoral necrosis factor.

The evidence of antibodies through the usual tests continues to cause concern where treated and probably parasitologically cured patients are still being tested positive. There is still no definite explanation for this and consequently some people give importance to a reduction in final figures, even though this only means that the serum has been 
diluted. Mathematically speaking these rates have no quantitative value.

Discrepant results noted in several laboratories and in infected people can probably be justified by the presence of different strains. In this respect, it would be well worth encouraging verification in experimental models through the parasitogram.

One thing is clear, none of us are happy with the situation. We have few therapeutic resources, which are precious in certain circumstances. The search for new efficient medicaments is of absolute importance. Nevertheless we have yet to see any real effort in this direction. Universities, the pharmaceutical industry and other institutions have done very little in this field, lamentably and wrongly considered to be less of a priority or less profitable. The small concern over these matters can be exemplified in the surprising act of interpreting the nitroimidazole MK-436 as experimentally efficient (Andrade et al. 1987, 1989). This compound of intracellular action had brought new hopes and was widely commented upon while the anti- $T$. cruzi therapy was being discussed, mainly because it was efficient with certain strains. I have nevertheless made an effort towards acquiring more information about it through Merck Sharp \& Dohme in which I was successful. This time I managed to obtain the support of the State of São Paulo authorities. However I was later on informed that the compound had failed the mutagenicity test which made the oncogenicity test unnecessary. This was the end of my short lived expectations. Currently some enthusiasm persists in the antiparasitic capacity of the triazole derivative referred to as ICI 195.739 which proved active in the experimental model based on applications made to mice. This derivative is currently being studied with the aim of being approved for use in infected patients (Urbina et al. 1996).

My exposition portrays a brief and general description of the current panorama in terms of etio- logical treatment of the infection caused by $T$. cruzi.. Our only option is to be aware of these problems and hope for some long awaited progress. As a consolation I would like to point out that for some other affections, even quite prevalent ones, therapeutic means have become more rare.

\section{REFERENCES}

Amato Neto V, Pasternak J, Uip DE 1995. Doença de Chagas no contexto dos transplantes de órgãos. Arq Bras Cardiol 65: 389-391.

Andrade SG, Silva RC, Santiago CMG 1989. Treatment of chronic experimental Trypanosoma cruzi infections in mice with MK-436, a 2-substituted 5nitromidazol. Bull WHO 67: 509-514.

Andrade SG, Silva RC, Santiago CMG, Freitas LAR 1987. Therapeutic action of MK-436 (2,5-nitroimidazole on Trypanosoma cruzi infections in mice: a parasitological, serological, histopathological, and ultrastructural study. Bull WHO 65: 625-633.

Levi GC, Lobo ISM, Kallás EG, Amato Neto V 1996. Etiological drug treatment of human infection by Trypanosoma cruzi. Rev Inst Med Trop São Paulo 38: 35-38.

Rassi A, Amato Neto V, Siqueira AF, Leite MSB 1998. Efeito protetor do nifurtimox contra a reativação parasitária em pacientes cronicamente infectados pelo Trypanosoma cruzi e tratados com corticóide em virtude de afecções associadas. Rev Soc Bras Med Trop 31: 249-255.

Sartori AMC, Shikanai-Yasuda MA, Amato Neto V, Lopes MH 1998. Follow-up of 18 patients with human immunodeficiency virus infection and chronic Chagas disease, with reactivation of Chagas disease causing cardiac disease in three patients. Clin Infect Dis 26: 177-179.

Souza ER, Amato Neto V, Braz LMA, Carignani FL, Okumura M 1998. Tratamento, por meio do alopurinol, da infecção aguda de camundongos pelo Trypanosoma cruzi. Rev Bras Clín Terap 24: 50-52.

Urbina JÁ, Payares G, Molina J, Sanoja C, Liendo A, Lazardi K, Piras MM, Piras M, Perez N, Wincker P, Ryley JF 1996. Cure of short-and long-term experimental Chaga disease using DO870. Science 273: 969-971. 